\title{
Simulated effects of changes in direct and diffuse radiation on canopy scale isoprene emissions from vegetation following volcanic eruptions
}

\author{
D. J. Wilton ${ }^{1,2}$, C. N. Hewitt ${ }^{2}$, and D. J. Beerling ${ }^{1}$ \\ ${ }^{1}$ Department of Animal and Plant Sciences, University of Sheffield, S10 2TN, UK \\ ${ }^{2}$ Lancaster Environment Centre, Lancaster University, Lancaster LA1 4YQ, UK
}

Received: 1 November 2010 - Published in Atmos. Chem. Phys. Discuss.: 1 March 2011

Revised: 27 October 2011 - Accepted: 9 November 2011 - Published: 23 November 2011

\begin{abstract}
Volcanic eruptions can alter the quality of incoming solar irradiance reaching the Earth's surface thereby influencing the interactions between vegetation and the Earth system. Isoprene $\left(\mathrm{C}_{5} \mathrm{H}_{8}\right)$ is a biogenic volatile organic compound emitted from leaves at a rate that is strongly dependent on the received flux of photosynthetically active radiation (PAR). We used a theoretical approach to investigate the potential for volcanic eruptions to change the isoprene flux from terrestrial forests using canopy-scale isoprene emission simulations that vary either the relative or absolute amount of diffuse $\left(I_{\mathrm{diff}}\right)$ and direct $\left(I_{\mathrm{dir}}\right)$ PAR. According to our simulations for a northern hardwood deciduous forest, if the total amount of PAR during summer remains constant while the proportion of $I_{\text {diff }}$ increases, canopy-scale isoprene emissions increase. This effect increases as leaf area index (LAI) increases. Simulating a decrease in the total amount of PAR, and a corresponding increase in $I_{\text {diff }}$ fraction, as measured during the 1992 Pinatubo eruption, changes daily total canopy-scale isoprene emissions from terrestrial vegetation in summertime by $+2.8 \%$ and $-1.4 \%$ for LAI of 6 and 2 , respectively. These effects have not previously been realized or quantified. Better capturing the effects of volcanic eruptions (and other major perturbations to the atmospheric aerosol content) on isoprene emissions from the terrestrial biosphere, and hence on the chemistry of the atmosphere, therefore may require inclusion of the effects of aerosols they produce on climate and the quality of PAR.
\end{abstract}

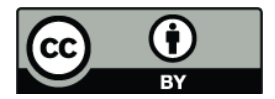

Correspondence to: D. J. Wilton (d.j.wilton@sheffield.ac.uk)

\section{Introduction}

A variety of biogenic volatile organic compounds (bVOCs) are produced and emitted by terrestrial ecosystems, with global bVOC fluxes far exceeding those of anthropogenic sources of VOCs (IPCC, 2007). The high chemical reactivity of bVOCs, and their high mass emission rates, gives rise to substantial impacts on atmospheric chemistry (Laothawornkitkul et al., 2009; Arneth et al., 2010). Atmospheric isoprene reacts with hydroxyl radicals that are the main sink of methane, which is an important greenhouse gas. Therefore changes in isoprene fluxes have an indirect influence on the amount of atmospheric methane (Fehsenfeld et al., 1992; IPCC, 2007). Estimates of above-canopy fluxes of isoprene $\left(\mathrm{C}_{5} \mathrm{H}_{8}\right)$ from terrestrial vegetation, and other reactive bVOCs, are required for quantitative Earth system studies. In particular, atmospheric chemistry models used to assess changes in tropospheric ozone and secondary aerosol formation (Carslaw et al., 2010) require realistic estimates of bVOC emission rates. Estimates of present-day global isoprene emissions from the terrestrial biosphere are typically 440-660 $\mathrm{TgCyr}^{-1}$ (Guenther et al., 1995, 2006; Lathiere et al., 2010). However, the fact that most models converge on a similar figure does not necessarily mean that the estimate is correct (Monson et al., 2007).

Experimental and field observations indicate that isoprene emissions from both individual leaves and the forest canopies are strongly dependent upon the amount of photosynthetically active radiation (PAR) received (Guenther et al., 1995, 2006). Empirical isoprene emission models therefore include a function of PAR, although it's partitioning into diffuse $\left(I_{\text {diff }}\right)$ and direct $\left(I_{\text {dir }}\right)$ fractions is not usually considered (Guenther et al., 1995, 2006). However, radiation from

Published by Copernicus Publications on behalf of the European Geosciences Union. 
the Sun is partially diffused by aerosol particles in the atmosphere, especially dust from volcanic eruptions (Farquhar and Roderick, 2003; Gu et al., 2003) via Mie scattering, elastic scattering due to particles larger than the wavelength of the radiation. Mie scattering occurs in addition to the Rayleigh scattering caused by atoms and molecules. Other sources of particles in the atmosphere, such as wind-blown dust, sea salt and secondary organic aerosols (SOA) from both anthropogenic and biogenic sources, also scatter light and reduce the total amount of solar radiation reaching the Earth's surface; a phenomenon known as global dimming (Wild, 2009). The amount of SOA formed in the atmosphere by the reactions of bVOCs is particularly uncertain (Carslaw et al., 2010) and depends in part on bVOC emissions rates. In addition to aerosols having a direct effect on global dimming by scattering radiation, they also have an indirect effect through the formation of cloud condensation nuclei.

A climate-biosphere feedback mechanism might operate if the amount of diffuse radiation significantly alters the emission of bVOCs. Scattered, i.e. diffuse $\left(I_{\text {diff }}\right)$, radiation, gives a more uniform irradiance through the canopy and penetrates deeper into the canopy to reach shaded leaves. Increases in $I_{\text {diff }}$, therefore, can enhance the productivity of vegetation at the canopy or ecosystem scales (Roderick et al., 2001; Osborne and Beerling, 2002; Gu et al., 2003; Farquhar and Roderick, 2003). At the global scale, Mercado et al. (2009) estimate that variation in $I_{\text {diff }}$ from 1960 to 1999 led to a $25 \%$ enhancement in net ecosystem exchange. Because isoprene emissions are partly dependent on the amount of radiation received by the leaf, this suggests that the complexity of the light environment must be considered in isoprene emission models, rather than just the total amount of PAR intercepted at the top of the canopy.

Volcanic eruptions inject enormous amounts of dust into the atmosphere that change the ratio $I_{\mathrm{diff}} / I_{\mathrm{dir}}$. Instrumental records showed attenuation of $I_{\mathrm{dir}}$, enhanced $I_{\text {diff }}$ and a peak global cooling of $0.4 \mathrm{~K}$ after the Pinatubo eruption (McCormick et al., 1995; Olmo et al., 1999). Given these observations, it is conceivable that changes to the relative amounts of $I_{\text {dir }}$ and $I_{\text {diff }}$ following major volcanic eruptions might alter the rate of canopy-scale isoprene emissions to the atmosphere, with potentially important consequences for the oxidative capacity of the troposphere (Telford et al., 2010).

Here we investigate this hypothesis using a theoretical treatment that involves modifying a radiative transfer scheme of an existing isoprene emissions model (Guenther et al., 2006) with the DePury and Farquhar (1997) treatment of $I_{\text {diff }}$ and $I_{\text {dir }}$ irradiating a vegetation canopy. DePury and Farquhar (1997) developed a photosynthesis model permitting calculation of $I_{\text {dir }}$ and $I_{\text {diff }}$ falling on the sunlit and shaded fractions of forest canopies. We undertook simulations for two case studies with this coupled model, both for an arbitrary $1 \mathrm{~m}^{2}$ area of land, with a range of leaf area indices (LAIs). These simulations are intended to examine the qualitative effects that changes in $I_{\text {diff }}$ and $I_{\text {dir }}$ may have on canopy isoprene emission rates of a hardwood forest. In Case 1, we consider the effects of varying the proportion of $I_{\text {diff }}$ with the total PAR flux remaining constant for a particular hour of the day. In Case 2, we simulate the effects of observed changes in $I_{\text {diff }} / I_{\text {dir }}$ during the summertime following the Pinatubo volcanic eruption on forest canopy isoprene emissions with a range of leaf area indices.

\section{Materials and methods}

Canopy-scale isoprene emission rates were calculated, following the method established by Guenther et al. (1995, 2006), as

Emission rate $=\varepsilon \gamma$

where $\varepsilon$ is an emission factor for a specific plant functional type at standard conditions (in $\mathrm{mg} \mathrm{Cm}^{-2} \mathrm{~h}^{-1}$ ), and $\gamma$ is the emission activity factor (dimensionless) which modifies the emission rate with functions of climate, environment and vegetation. The emission activity factor $\gamma$ is given by:

$\gamma=\gamma_{t} \times \gamma_{\text {LAI }} \times \gamma_{p}$

where $\gamma_{t}, \gamma_{\text {LAI }}$ and $\gamma_{p}$ are factors for temperature, LAI and PAR, respectively. Other factors can be included (soil moisture and leaf age, for example), but our calculations here address the specific hypothesis that different relative amounts of $I_{\mathrm{dir}}$ and $I_{\mathrm{diff}}$ affect isoprene emission rates. We use the function for $\gamma_{t}$ adopted in the standard version of MEGAN (Guenther et al., 2006), which depends upon hourly and daily average temperatures. To focus on radiation effects, we keep temperature fixed throughout the day at an appropriate daily average. The term $\gamma_{t}$ is therefore a constant and included to give calculated emission rates that more closely resemble actual rates.

For PAR and LAI we consider the canopy to be divided into sunlit and shaded fractions which are differently affected by direct and diffuse radiation (DePury and Farquhar, 1997). Isoprene emission rates for the sunlit and shaded fractions are calculated separately. For a given value of LAI, the sunlit fraction is given by Guenther et al. (1995):

$\mathrm{LAI}_{\text {sun }}=\mathrm{LAI} \times[1-\exp (-0.5 \times \mathrm{LAI} / \sin \beta)] \times \sin \beta$

and the shaded LAI is simply:

$\mathrm{LAI}_{\text {shade }}=\mathrm{LAI}-\mathrm{LAI}_{\text {sun }}$

where $\beta$ is the solar angle, obtained from solar geometry equations for a given latitude, day of the year and hour of the day. We then calculate $\gamma_{\text {LAI }}$ after Guenther et al. (2006):

$\gamma_{\mathrm{LAI}}=0.49 \times \mathrm{LAI} / \sqrt{\left(1+0.2 \times \mathrm{LAI}^{2}\right)}$ 
By substituting $\mathrm{LAI}_{\text {sun }}$ or $\mathrm{LAI}_{\text {shade }}$ for $\mathrm{LAI}$ into Eq. (5), we calculate emissions from the sunlit or shaded fractions of canopy, respectively.

To calculate $\gamma_{p}$ we follow Guenther et al. (2006), where the equation is dependent upon hourly $(P)$, daily average $\left(P_{24}\right)$ and the previous $10 \mathrm{~d}$ average $\left(P_{240}\right)$ values of radiation, with a different constant $\left(P_{0}\right)$ adopted for sunlit and shaded parts.

$$
\gamma p=C p\left[(\alpha \times P) / \sqrt{ }\left(1+\alpha^{2} \times P^{2}\right)\right]
$$

$\alpha=0.004-0.0005 \times \ln \left(P_{240}\right)$

$C p=0.0468 \times \exp \left(0.0005 \times\left(P_{24}-P_{0}\right)\right) \times P_{240}^{0.6}$

Derivation of the equations for the calculation of direct, diffuse, sunlit and shaded PAR is given in DePury and Farquhar (1997), including terms for reflected and scattered PAR. We therefore calculate an emission rate for the sunlit and shaded fractions of the canopy separately using the appropriate sunlit and shaded PAR, for all $\mathrm{P}$ terms in Eqs. (6) to $(8)$ and the appropriate sunlit or shaded LAI for $\gamma_{\mathrm{LAI}}$.

\subsection{Model calculations}

Case 1. Fixed $I_{\text {tot }}$ variable $I_{\text {diff }}$. We first consider canopy isoprene emissions for differing $I_{\text {dir }}$ and $I_{\text {diff }}$ using calculated values of radiation, as per DePury and Farquhar (1997). We calculate $I_{\text {dir }}$ and $I_{\text {diff }}$ for a given hour of the day, and use these values to calculate isoprene emission rates. The calculations procedure is then repeated, reducing $I_{\text {dir }}$ by up to $40 \%$ of its initial value and increasing $I_{\text {diff }}$ such that the total radiation remains the same. This allows investigation of how emission rates vary with changing proportions of direct and diffuse radiation. We calculated isoprene emissions over a single day with an hourly time step (choosing the 195th day of the year) for $1 \mathrm{~m}^{2}$ area of land surface, at a latitude of $42.5^{\circ} \mathrm{N}$, temperature of $293 \mathrm{~K}$, and $\varepsilon=10 \mathrm{mg}$ isoprene $\mathrm{m}^{-2} \mathrm{~h}^{-1}$ and LAIs 2,4 and $6 \mathrm{~m}^{2}$ leaf $\mathrm{m}^{-2}$ land surface. These environmental conditions, and the emission factor, represent a deciduous broad-leaved forest on a summer day in the Northern Hemisphere.

Case 2. Pinatubo. Variable $I_{\text {tot }}$ and $I_{\text {diff }}$. Gu et al. (2003) reported measurements of direct and diffuse radiation in the years following the eruption of Mount Pinatubo in 1991, which was the largest eruption in the last 100 years, and injected vast amounts of aerosol particles into the troposphere and stratosphere (including ca. $2 \times 10^{7} \mathrm{t}$ of $\mathrm{SO}_{2}$, some of which oxidizes in the atmosphere to form sulphate aerosol). We therefore used a second approach to simulating the effect of changes in $I_{\text {dir }}$ and $I_{\text {diff }}$ on canopy-scale isoprene emissions using curves fitted to the data of Gu et al. (2003), which were obtained during (1992) and after (1994) the Pinatubo eruption under cloudless skies in a northern hardwood forest $\left(42.5^{\circ} \mathrm{N}, 2072.2^{\circ} \mathrm{W}\right)$ (Fig. 1). We take the 1992 curves to represent a relatively dusty atmosphere, where the amount
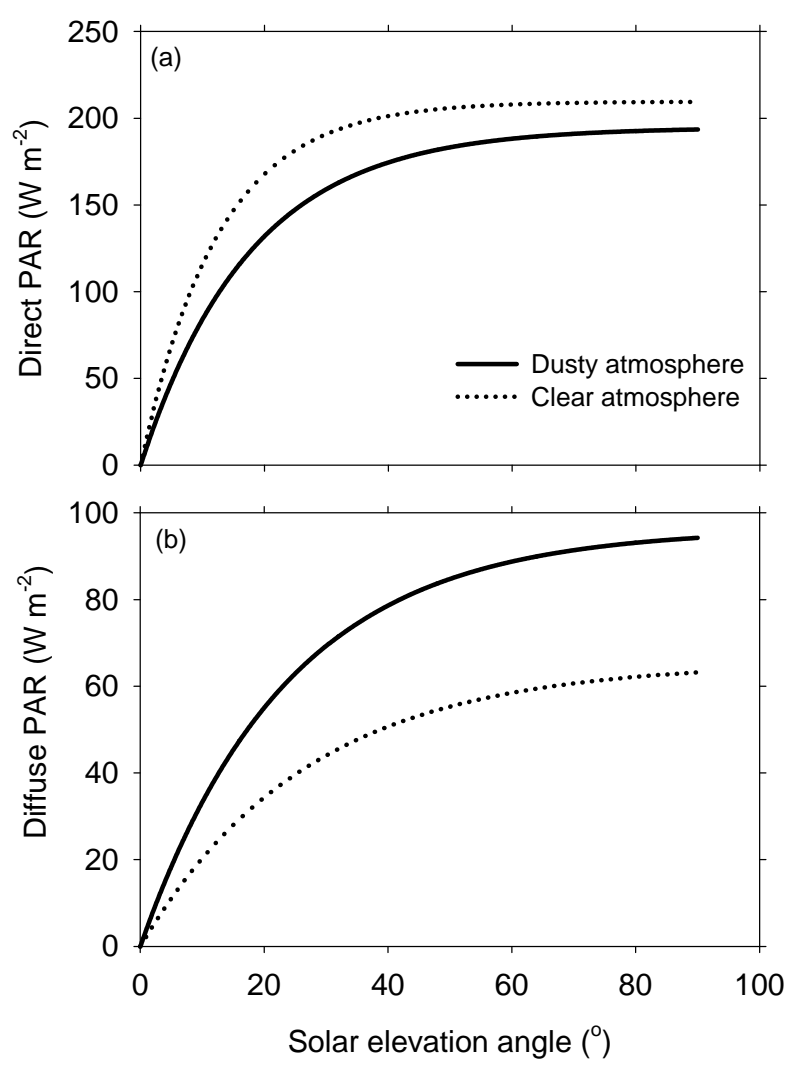

Fig. 1. Variation of direct (a) and diffuse (b) PAR as a function of solar angle in dusty (1992) and clear (1994) atmospheres. The curves are given by Direct PAR, dusty atmosphere $=194.7(1-$ $\left.e^{-0.05664 \beta}\right)$, Diffuse PAR, dusty atmosphere $=96.4\left(1-e^{-0.0423 \beta}\right)$, Direct PAR, clear atmosphere $=209.6\left(1-e^{-0.08061 \beta}\right)$, Diffuse PAR, clear atmosphere $=65.2\left(1-e^{-0.03712 \beta}\right)$, where $\beta$ is the solar angle. Based on data from $\mathrm{Gu}$ et al. (2003).

of diffuse radiation will be higher than normal and the 1994 curves to represent a clear atmosphere where the amount of diffuse radiation will be more like normal. Note that the terms dusty and clear in this context are relative.

The radiation responses (Fig. 1) are similar to those for global solar radiation (Gu et al., 2003) and are scaled to convert them to PAR, such that for the clear atmosphere they give the same maximum values of $I_{\mathrm{dir}}$ and $I_{\mathrm{diff}}$ (as in Case 1). For the dusty atmosphere they are further scaled by the ratio of the maximum global solar radiation in the dusty atmosphere over that for a clear atmosphere. The curves in Fig. 1 therefore provide $I_{\mathrm{dir}}$ and $I_{\mathrm{diff}}$ changes for calculating PAR for the sunlit and shaded LAI fractions and computing canopy isoprene emissions. These data indicate $I_{\text {diff }}$ increases by $50 \%$ to $70 \%$ and $I_{\text {dir }}$ decreases by $30 \%$ to $9 \%$ between dawn/dusk and midday (Fig. 1). Environmental conditions and isoprene emission factors are as for Case 1, i.e. a midsummer day to be consistent with Gu et al.'s (2003) measurements. 


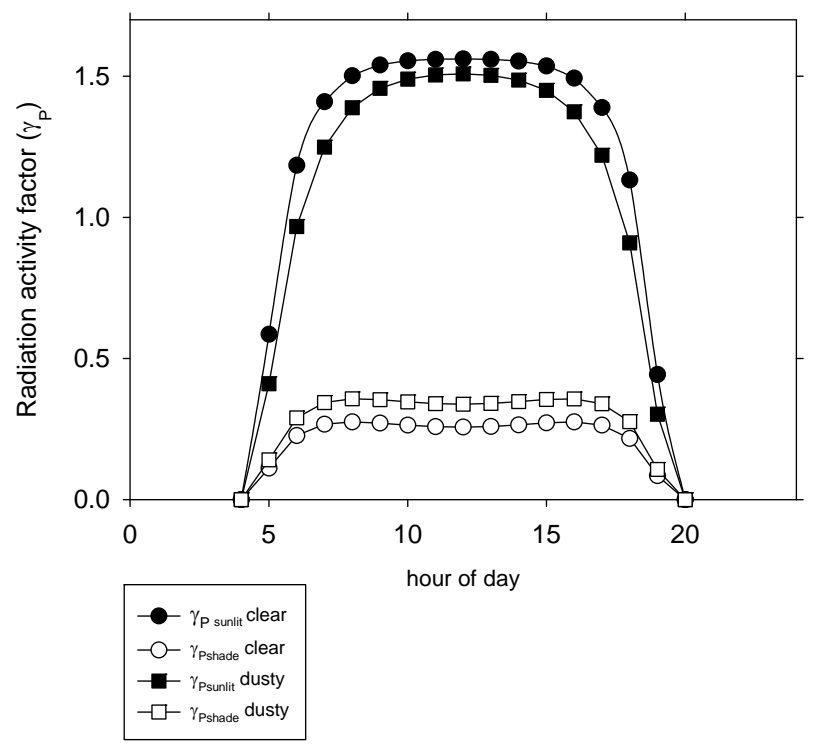

Fig. 2. Variation of $\gamma_{p}$ for the sunlit and shaded fractions of the canopy in clear and dusty atmosphere with respect to hour of the day, with $\mathrm{LAI}=6$.

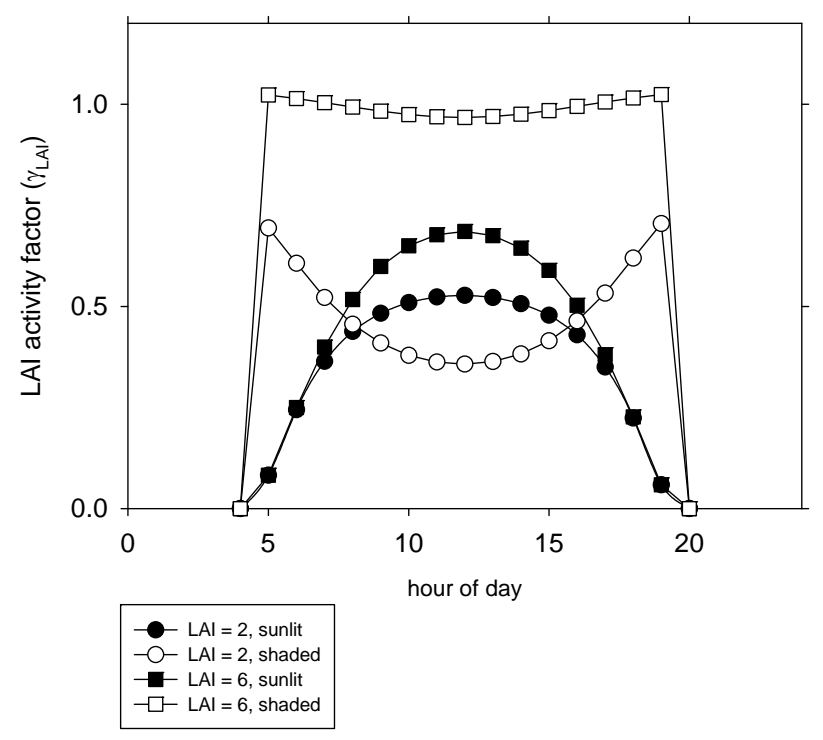

Fig. 3. Variation of $\gamma_{\text {LAI }}$ with respect to hour of the day for sunlit and shaded fraction and for LAI of 2 and 6.

Figures 2 and 3, respectively, depict variations in $\gamma_{P}$, the radiation activity factor (Eq. 6), and $\gamma_{\mathrm{LAI}}$, the leaf area activity factor (Eq. 5) of the sunlit and shaded canopy with the hour of the day. These two variables show different responses. The term $\gamma_{P}$ varies with hour of the day as the total amount of radiation increases and decreases, with the timing of the peak value in shaded radiation slightly before and after midday because of its greater dependency upon diffuse radiation. Figure 3 shows $\gamma_{\text {LAI }}$ varies simply with respect to hour of the day. As the solar angle increases from dawn to midday more of the canopy intercepts direct sunlight causing a decrease in the shaded fraction. The reverse situation occurs between midday and dusk. Increasing LAI from 2 to 6 increases $\gamma_{\text {LAI }}$, but the shaded component increases more because a higher LAI means more leaf area is located below the upper canopy.

\section{Results and discussion}

Our Case 1 sensitivity analyses indicate that increasing the amount of $I_{\text {diff }}$ relative to the total PAR, such that $I_{\text {dir }}$ is reduced by $40 \%$, decreases isoprene emissions from the sunlit fraction of the canopy by 7-9\% (Fig. 4a) and increases emissions from the shaded fraction by $35-40 \%$ (Fig. 4b). Overall, the differential effects of increases in the relative amount of $I_{\text {diff }}$ on emissions from the sunlit and shaded fractions of the canopy result in a small net increase in the daily total isoprene emissions (Fig. 4c). There is a small effect of LAI on the response because higher LAIs generate more shaded leaf area per unit area of land, and an increase in $I_{\text {diff }}$ means radiation penetrates to a greater fraction of the shaded leaves (Roderick et al., 2001; Farquhar and Roderick, 2003). Sustained changes in the quality of solar radiation over the growing season might therefore alter isoprene emissions from forest canopies, in addition to their well established effects on photosynthesis and productivity (Roderick et al., 2001; Osborne and Beerling, 2002; Gu et al., 2003; Farquhar and Roderick, 2003).

Results from the calculations under the conditions given by Case 2 , driven by observations, represent a first-order simulation of the possible effects of the eruption of Mount Pinatubo on isoprene emissions arising solely from changes in the nature and quality of solar radiation. Calculated canopy isoprene emission calculations for this more realistic scenario were undertaken with LAI = 2 and 6 in dusty (1992) and clear (1994) atmospheres. We report the hourly variations in emissions because the proportion of $I_{\text {diff }}$ radiation varies with time of day (Fig. 5a-d) (Roderick et al., 2001). When expressed as the difference between emissions in a dusty and clear atmosphere, our results (Fig. 5b,d) reveal that emissions from the sunlit fraction of the canopy decrease, and those from the shaded fraction increase, for all hours of the day, irrespective of LAI. These responses reflect changes in $\gamma_{P}$ between clear and dusty skies (Fig. 2) for the sunlit and shaded fractions of the canopy because $\gamma_{\text {LAI }}$ in Eq. (5) is unaffected by atmospheric conditions. A larger increase in isoprene emissions from the shaded portion of the canopy is evident at $\mathrm{LAI}=6$ (Fig. 5d) than at LAI $=2$ (Fig. 5b) because of the proportionally higher $\mathrm{LAI}_{\text {shade }}$ at $\mathrm{LAI} 6$. At $\mathrm{LAI}=6$, total canopy isoprene emissions increase for all hours of the day, whereas at $\mathrm{LAI}=2$ emissions only increase around midday, 
Table 1. Total daily canopy isoprene emissions for $1 \mathrm{~m}^{2}$ in clear atmosphere and dusty atmosphere with a range of reductions in temperature.

\begin{tabular}{|c|c|c|c|c|c|}
\hline \multirow[t]{2}{*}{ LAI } & \multirow{2}{*}{$\begin{array}{r}\text { Clear atmosphere } \\
T=293.0 \mathrm{~K}\end{array}$} & \multicolumn{4}{|c|}{ Dusty atmosphere } \\
\hline & & $T=293.0 \mathrm{~K}$ & $T=292.5 \mathrm{~K}$ & $T=292.0 \mathrm{~K}$ & $T=291.5 \mathrm{~K}$ \\
\hline 2 & 21.7 & 21.4 & 20 & 18.71 & 17.53 \\
\hline 4 & 35.01 & 35.6 & 33.37 & 31.24 & 29.24 \\
\hline 6 & 39.83 & 40.9 & 38.33 & 35.89 & 33.6 \\
\hline
\end{tabular}

with reductions from the sunlit fraction during the rest of the day leading to a net daily decrease in emissions.

In terms of total isoprene emitted from the canopy per day, we calculate 21.7 and $21.4 \mathrm{mg} \mathrm{C} \mathrm{m}^{-2}$ for $\mathrm{LAI}=2$ in the clear and dusty atmospheres, respectively, and 39.8 and $40.9 \mathrm{mg} \mathrm{C} \mathrm{m}^{-2}$ for $\mathrm{LAI}=6$. These numbers represent a percentage change of $-1.4 \%$ for $\mathrm{LAI}=2$ and $+2.8 \%$ for $\mathrm{LAI}=6$. Reductions in temperature associated with increase in atmospheric dust are also likely to exert a direct effect on emission rates (Telford et al., 2010). At LAI $=2$, a $1.5^{\circ} \mathrm{C}$ reduction in average daily temperature, similar to that observed (Telford et al., 2010), combined with changes in the quality of radiation in a dusty atmosphere, reduced canopy isoprene emissions by $19 \%$ compared to $1.3 \%$ for radiation-only effects (Table 1). However, the synergistic effects of cooler temperatures and altered radiation are far less marked at higher LAIs (Table 1) that cast more shade. As most isoprene emitted by the terrestrial biosphere is released from tropical forests with high LAI, these results suggest that changes in diffuse and direct radiation might attenuate reductions in global bVOC emissions due to cooling. This possibility remains to be quantified, however, because of our focus a specific temperate forest location during midsummer.

Examining the relative change in isoprene emissions between clear to dusty skies, i.e. [(emissions in dusty skyemissions in clear sky)/emissions in clear sky] (Fig. 6) reveals emissions for the sunlit fraction are quite similar at low and high LAIs, but with larger differences for the shaded fractions. However, changes to the total emissions are very small, $-0.3 \mathrm{mg} \mathrm{C} \mathrm{m}^{-2} \mathrm{~d}^{-1}$ for $\mathrm{LAI}=2$, where the increase from the shaded fraction $\left(0.8 \mathrm{mg} \mathrm{C} \mathrm{m}^{-2} \mathrm{~d}^{-1}\right)$ is almost balanced out by the decrease from the sunlit fraction $\left(-1.1 \mathrm{mg} \mathrm{C} \mathrm{m}^{-2} \mathrm{~d}^{-1}\right)$. At $\mathrm{LAI}=6$ emissions increase by $1.1 \mathrm{mg} \mathrm{C} \mathrm{m}^{-2} \mathrm{~d}^{-1}$ because the increase in shaded emissions (3.0 $\mathrm{mg} \mathrm{C} \mathrm{m}^{-2} \mathrm{~d}^{-1}$ ) exceeds the decrease in sunlit emission $\left(-1.9 \mathrm{mg} \mathrm{C} \mathrm{m}^{-2} \mathrm{~d}^{-1}\right)$.

We also report isoprene emission rates with respect to the ratio $I_{\text {diff }} / I_{\text {dir }}$, based on the simulation results for Case 2 (Fig. 7). Note that this ratio is highest in a dusty atmosphere which contains more particles that scatter radiation to create diffuse light. Maximum sunlit emission rates occur at the highest value of $I_{\text {diff }} / I_{\text {dir }}$, which corresponds to midday, when direct radiation is greatest. Maximum emission rates for the shaded fraction occur at lower values of
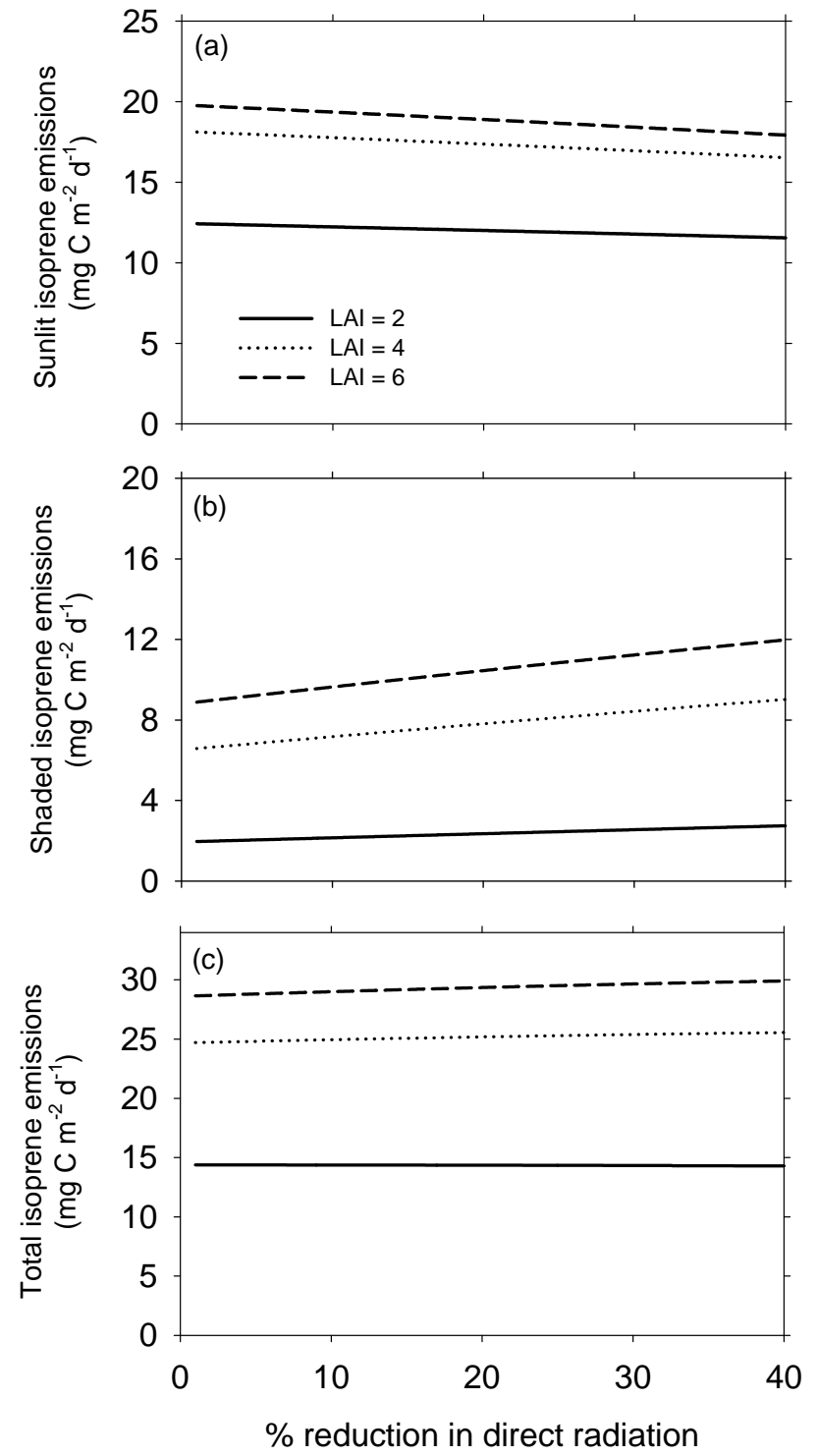

Fig. 4. Calculated daily variations in (a) sunlit, (b) shaded, and (c) total canopy isoprene emissions as the proportion of $I_{\text {dir }}$ decreases with a corresponding increase in $I_{\text {diff }}$ such that the total PAR remains constant for a particular hour. Results are shown for a range of leaf area indices (LAIs). All other conditions are as given in main text. 
(a) clear atmosphere, $\mathrm{LAI}=2$

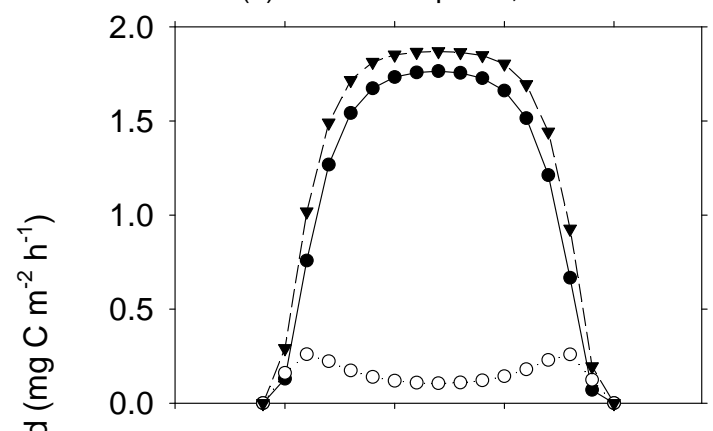

(b) dusty minus clear atmosphere-, LAI = 2

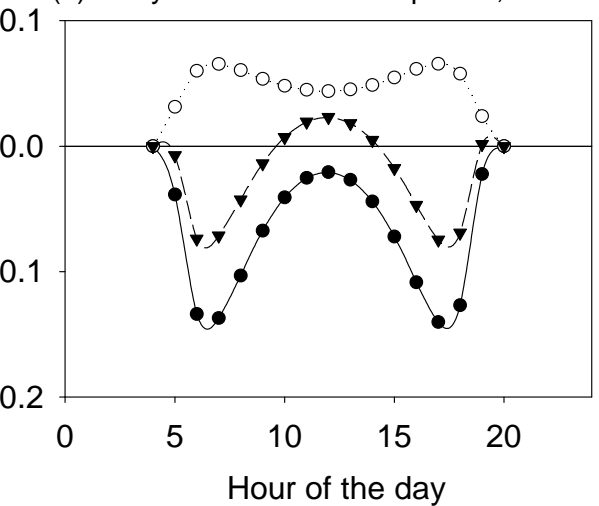

(c) clear atmosphere, $\mathrm{LAI}=6$

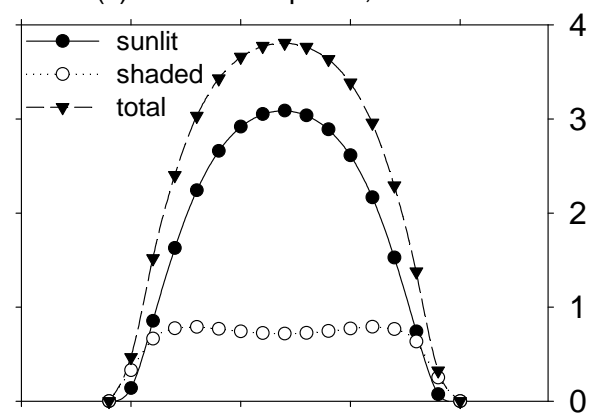

(d) dusty minus clear atmosphere, LAI $=6$

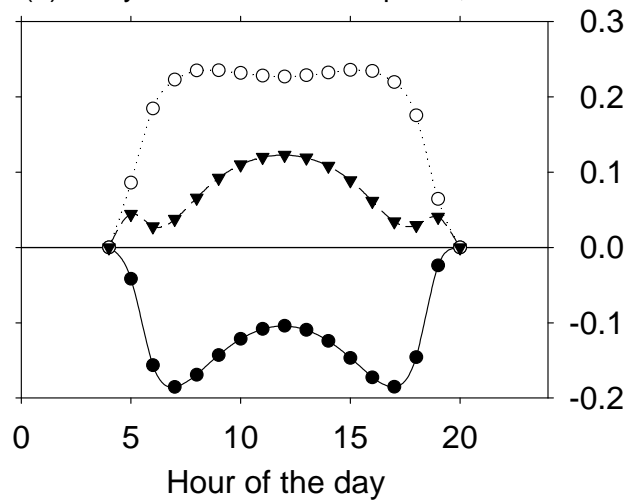

Fig. 5. Hourly variation in sunlit and shaded isoprene emission for $1 \mathrm{~m}^{2}$ and changes in those emissions produced by going from a clear to dusty atmosphere. (a) and (b) for $\mathrm{LAI}=2$, isoprene emissions in clear atmosphere, and emission changes due to dusty atmosphere, respectively. (c) and (d) are the corresponding plots for $\mathrm{LAI}=6$.

$I_{\text {diff }} / I_{\text {dir }}$ corresponding to times closer to dawn or dusk, as a result of the midday minimum in $\gamma_{\text {LAI }}$ (Fig. 3). When the ratio $I_{\mathrm{diff}} / I_{\mathrm{dir}}$ is very low, shaded emissions are greater than sunlit emissions, but as the ratio increases to cross a threshold, sunlit emissions exceed shaded emissions. The location of a particular $I_{\mathrm{diff}} / I_{\mathrm{dir}}$ emission threshold depends upon LAI and the quality of the atmosphere. In a clear atmosphere and $\mathrm{LAI}=6$, the threshold is equal to 0.18 , and for $\mathrm{LAI}=2$ to 0.16 . In a dusty atmosphere and $\mathrm{LAI}=6$, the threshold is equal to 0.41 and for $\mathrm{LAI}=2$ to 0.39 . We recognize that these results may be model dependent but they highlight the possibility that thresholds in the nature of the light environment may represent important controls on forest isoprene emissions.

Figure 8 shows the absolute changes in isoprene emission rate in clear and dusty atmospheres, with respect the relevant PAR for Case 2. The size of the points indicates the magnitude of the change and their orientation indicates the sign of the change. For the shaded canopy, emission rates increase as PAR increases, whereas for the sunlit canopy they decrease as PAR increases (Fig. 8 a,b). For example, with $\mathrm{LAI}=6$, shaded emission rates increase from 0.06 to $0.23 \mathrm{mg} \mathrm{C} \mathrm{m}^{-2} \mathrm{~h}^{-1}$ as PAR (clear) rises from 14 to $46 \mathrm{~W} \mathrm{~m}^{-2}$, but sunlit emission rates decrease from -0.02 to $-0.12 \mathrm{mg} \mathrm{C} \mathrm{m}^{-2} \mathrm{~h}^{-1}$ as PAR (clear) rises from 48 to $216 \mathrm{~W} \mathrm{~m}^{-2}$. The greatest decrease of $-0.19 \mathrm{mg} \mathrm{C} \mathrm{m}^{-2} \mathrm{~h}^{-1}$ occurs at PAR (clear) $=185 \mathrm{~W} \mathrm{~m}^{-2}$. This can be understood by considering the difference between direct PAR, which most strongly influences sunlit PAR, in dusty and clear atmosphere (Fig. 1a) up to a solar angle of ca. $30^{\circ}$. Therefore, although PAR is clearly greatest when the solar angle is greatest, this does not correspond to the greatest difference between clear and dusty atmospheres, and hence does not correspond to the greatest difference in emissions for the sunlit canopy. For diffuse PAR (Fig. 1b), which most strongly affects shaded PAR, the difference between the clear and dusty atmosphere always increases as solar angle increases, and therefore the greatest difference in shaded emission rate occurs when shaded PAR is greatest.

The primary aim of this paper is to investigate the effects that varying amounts of direct and diffuse radiation may have on canopy isoprene emission for which few canopy measurements exist. However, for a clear atmosphere, the model can be evaluated by comparing predictions with measurements reported by Goldstein et al. (1998) from the same Harvard forest site as measurements of radiation (Gu et al., 2003). Calculated isoprene emission rates were undertaken with the model run as in Case 2, but with an LAI for the Harvard for- 
(a)

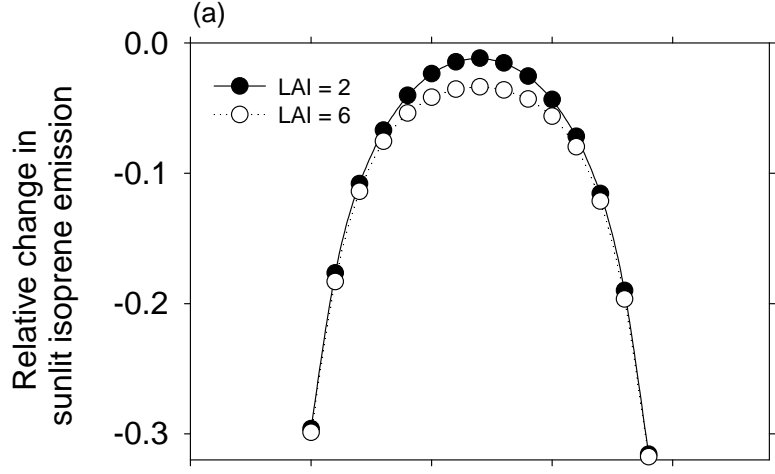

(b)

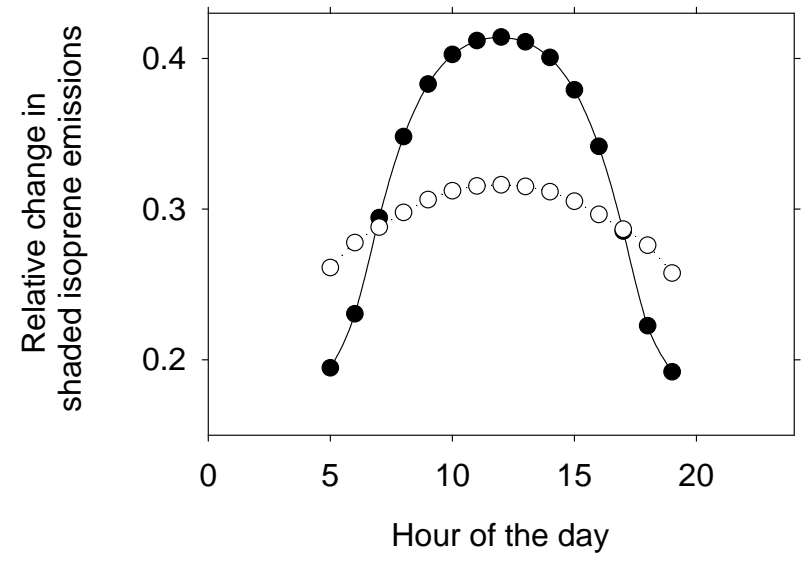

Fig. 6. Relative change in isoprene emission for $1 \mathrm{~m}^{2}$ over the course of a day for (a) sunlit and (b) shaded fractions of the canopy, calculated for an $\mathrm{LAI}=2$ and 6 . Relative change is given as [(emissions in dusty sky - emissions in clear sky)/emissions in clear sky].

est site of 4.5 (Wythers et al., 2003) and an emission factor of $12.6 \mathrm{mg}$ isoprene $\mathrm{m}^{-2} \mathrm{~h}^{-1}$ (Guenther et al., 2006), taken as the global average emission factor for broad-leaved tree species in Harvard forest (Goldstein et al., 1998; Wythers et al., 2003). As the observations reported by Goldstein et al. (1998) are the mean for June through to October, the model was run at the midpoint date of 15 August, with an average temperature of $289 \mathrm{~K}$ and a variation of $\pm 3 \mathrm{~K}$ (Goldstein et al., 1998). Overall, model results are in good agreement with observations (Fig. 9), capturing diurnal canopy isoprene emissions. We calculate a total daily isoprene emission of $27.8 \mathrm{mg} \mathrm{C} \mathrm{m}^{-2} \mathrm{~d}^{-1}$ which compares favourably to $28.2 \mathrm{mg} \mathrm{C} \mathrm{m}^{-2} \mathrm{~d}^{-1}$ estimated by Goldstein et al. (1998) from their observations.

Telford et al. (2010) calculated changes in isoprene emissions from the terrestrial biosphere, and modelled their impact on atmospheric chemistry, following the Mount Pinatubo eruption in 1991. These authors modelled a $9 \%$ reduction in global isoprene emissions during the early 1990s $\left(40 \mathrm{Tg} \mathrm{C}\right.$ year $\left.^{-1}\right)$, caused by the cooler, drier climate and a (a) clear atmosphere

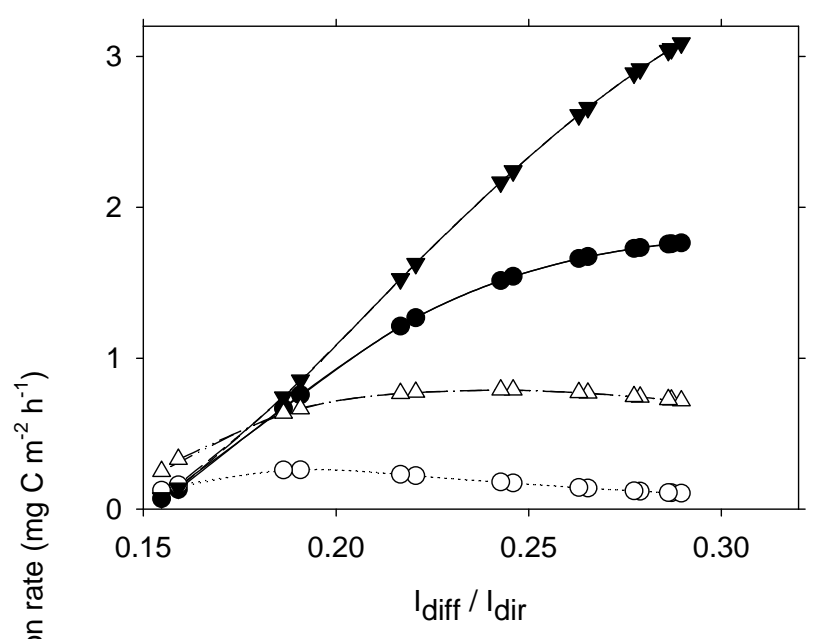

(b) dusty atmosphere

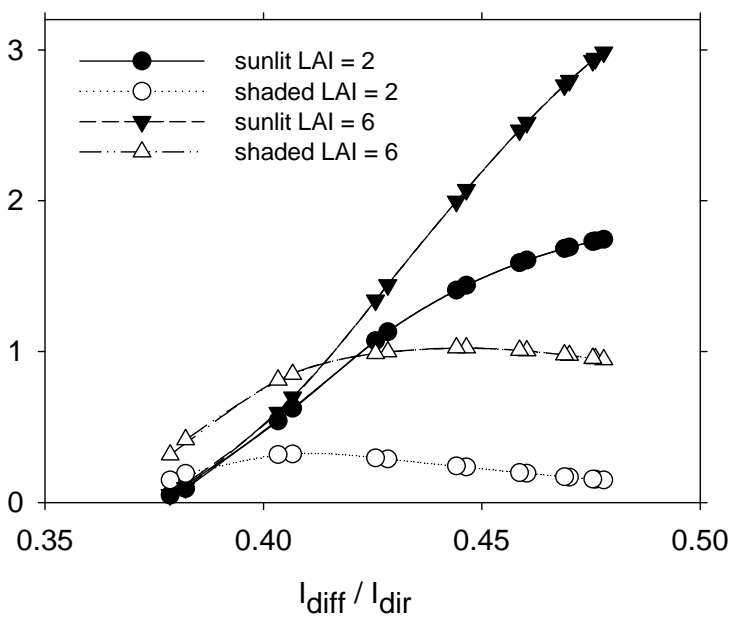

Fig. 7. Variation in isoprene emission rates with respect the ratio $I_{\text {diff }} / I_{\text {dir }}$ for (a) a clear atmosphere and (b) a dusty atmosphere.

reduction in total PAR following the eruption. Our results indicate that explicit consideration of summertime changes in the nature of the PAR following the eruption of Mount Pinatubo (McCormick et al., 1995) could partially offset this reduction, thereby reducing the enhanced sink for methane through increased tropospheric hydroxyl abundance. Earlier estimates of the enhanced sink for methane after 1990 due to reductions in isoprene fluxes from the terrestrial biosphere of up to $5 \mathrm{Tg}\left(\mathrm{CH}_{4}\right) \mathrm{yr}^{-1}$ (Telford et al., 2010) may therefore overestimate indirect vegetation effects on the reduced growth rate of atmospheric methane (Dlugokencky et al., 2003). 
(a) $\mathrm{LAI}=2$

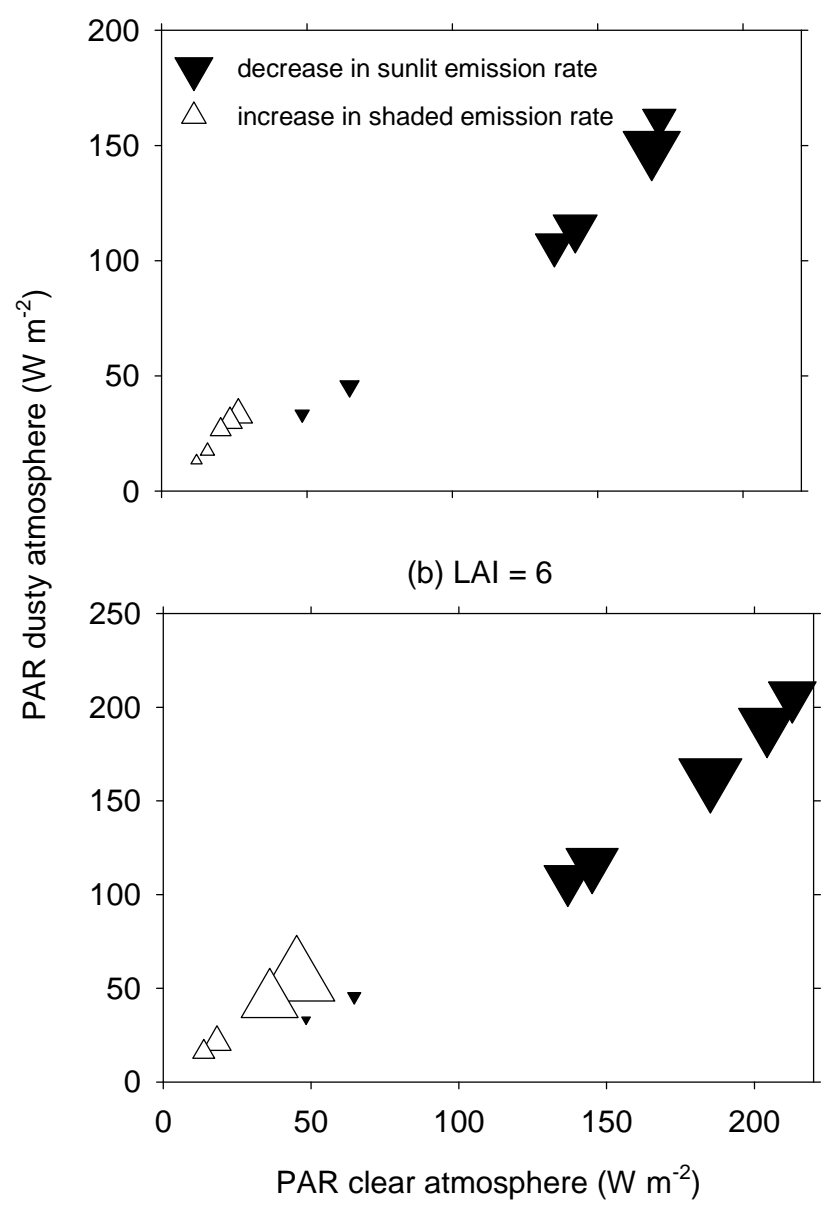

Fig. 8. Changes in isoprene emission rate plotted with respect to the relevant PAR in clear and dusty atmosphere for (a) LAI $=2$ and (b) $\mathrm{LAI}=6$. For sunlit emissions, we plot sunlit PAR in dusty atmosphere against sunlit PAR in clear atmosphere, and similarly shaded PAR is used for shaded emissions. The size of the points indicates the magnitude of the change in emission rate going from clear to dusty atmosphere and the orientation of the triangles indicates increase (upward pointing) or decrease (downward pointing) in emission rate. The scale of the emission rate changes are from -0.04 to $-0.14 \mathrm{mg} \mathrm{C} \mathrm{m}^{-2} \mathrm{~h}^{-1}$ for sunlit and 0.02 to $0.06 \mathrm{mg} \mathrm{C} \mathrm{m}^{-2} \mathrm{~h}^{-1}$ for shaded in (a). The scale is the same for (b).

\section{Conclusions}

Following the eruption of Mount Pinatubo and the injection of diffusing particles into the atmosphere $I_{\mathrm{dir}}$ decreased by $30 \%$ at dawn and dusk and $9 \%$ at midday, whereas $I_{\text {diff }}$ increased $70 \%$ at dawn and dusk and over $50 \%$ at midday. Simulation of these changes in the quality of PAR changed daily total canopy-scale isoprene emissions from a northern hardwood deciduous forest in summertime by $+2.8 \%$ and $-1.4 \%$ for LAI of 6 and 2 , respectively. These results sug-

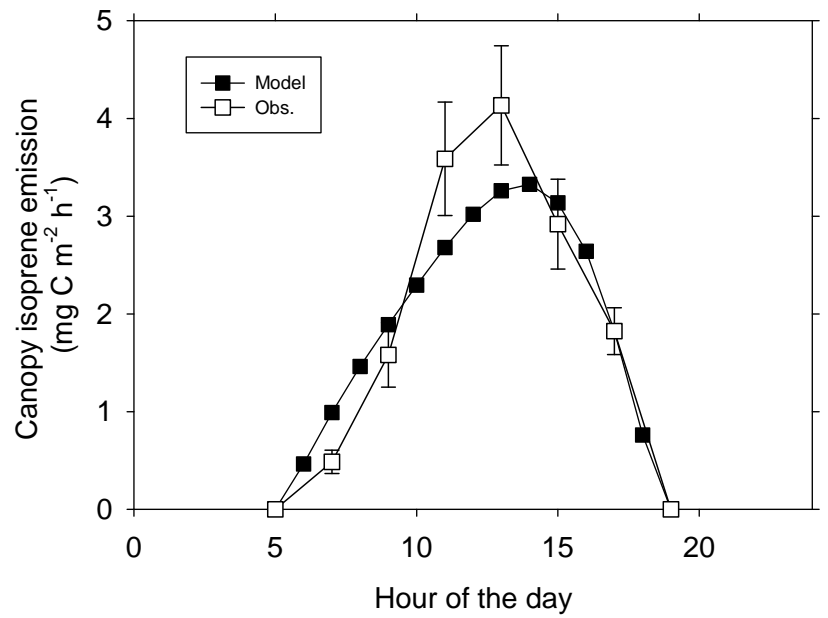

Fig. 9. Comparison between modelled isoprene emission rates for the Harvard forest site in a clear atmosphere with observations (Goldstein et al., 1998). Bars indicate standard errors of observations averaged over $2 \mathrm{~h}$ time windows.

gest variations in $I_{\text {diff }}$ and $I_{\text {dir }}$ following volcanic eruptions may represent a missing component in modelling the environmentally driven emissions of biogenic VOCs and their interaction with the Earth system. At the present time it is not possible to test our theoretical predictions of how changes in $I_{\text {diff }} / I_{\text {dir }}$ affect isoprene emission rates with observations from the field. However, the model we have used produces emissions for a clear atmosphere in good agreement with observations for a temperate forest. The calculated effects we report here may be amplified if changes in $I_{\text {diff }}$ alter the basal emission factors for leaves in shaded or sunlit fractions of the canopy. We are not aware of any such differences, but our model calculations provide a basis for investigations through large-scale laboratory experiments.

Acknowledgements. We thank Andrew Jarvis and Annette Ryan for initiating our interest in this area, Lianhong $\mathrm{Gu}$ for information on radiation at Harvard forest, and the Natural Environment Research Council for funding under the QUEST directed programme (NE/C001672/1). We thank Kirsti Ashworth and two anonymous referees for their comments in improving this paper.

Edited by: M. Kanakidou

\section{References}

Arneth, A., Harrison, S. P., Zaehle, S., Tsigaridis, K., Menon, S., Bartlein, P. J., and Feichter, J.: Terrestrial biogeochemical feedbacks in the climate system, Nature Geosci., 3, 525-532, 2010.

Carslaw, K. S., Boucher, O., Spracklen, D. V., Mann, G. W., Rae, J. G. L., Woodward, S., and Kulmala, M.: A review of natural 
aerosol interactions and feedbacks within the Earth system, Atmos. Chem. Phys., 10, 1701-1737, doi:10.5194/acp-10-17012010, 2010.

DePury, D. G. G and Farquhar, G. D.: Simple scaling of photosynthesis from leaves to canopies without the errors of big-leaf models, Plant, Cell, Environ., 20, 537-557, 1997.

Dlugokencky, E., Houweling, S., Bruhwiler, L., Masarie, K. A., Lang, P. M., Miller, J. B., and Tans, P. P.: Atmospheric methane levels off: temporary pause or new steady-state ?, Geophy. Res. Lett., 30, GL018126, doi:10.1029/2003GL018126, 2003.

Farquhar, G. D. and Roderick, M. L.: Pinatubo Diffuse Light and the carbon Cycle, Science, 299, 1997-1998, 2003.

Fehsenfeld, F. C., Calvert, J., Fall, R., Goldan, P., Guenther, A., Hewitt, C. N., Lamb, B., Liu, S., Trainer, M., Westberg, H., and Zimmerman, P.: Emissions of volatile organic compounds from vegetationand their implications for atmospheric chemistry, Global Biogeochem. Cy. 6, 389-430, 1992.

Goldstein, A. H., Goulden, M. L., Munger, W., Wofsy, S. C., and Geron, C. D.: Seasonal course of isoprene emissions from a midlatitude forest, J. Geophys. Res, 103, 31045-31056, 1998.

Gu, L., Baldocchi, D. D., Wofsy, S. C., Mugner, J. W., Michalsky, J. J., Urbanski, S. P., and Boden, T. A.: Response of a deciduous forest to the Mount Pinatubo eruption: enhanced photosynthesis, Science, 299, 2035-2038, 2003.

Guenther, A., Hewitt, C.N., Erickson, D., Fall, R., Geron, C., Graedel, T., Harley, P., Klinger, L., Lerdau, M., McKay, W.A., Pierce, T., Scholes, B., Steinbrecher, R., Tallamraju, R., Taylor, J. and Zimmerman, P.: A global model of natural volatile organic compound emissions, J. Geophys. Res, 100, 8873-8892, 1995.

Guenther, A., Karl, T., Harley, P., Wiedinmyer, C., Palmer, P. I., and Geron, C.: Estimates of global terrestrial isoprene emissions using MEGAN (Model of Emissions of Gases and Aerosols from Nature), Atmos. Chem. Phys., 6, 3181-3210, doi:10.5194/acp-63181-2006, 2006.

Intergovernmental Panel on Climate Change [IPCC] Climate Change 2007: The Physical Science Basis. Contribution of Working Group I to the Fourth Assessment Report of the Intergovernmental Panel on Climate Change, edited by: Solomon, S., Qin, D., Manning, M., Chen, Z., Marquis, M., Averyt, K. B., Tignor, M., and Miller, H. L., Cambridge University Press, Cambridge, UK, 129-234, 2007.
Laothawornkitkul, J., Taylor, J. E., Paul, N. D. and Hewitt, C. N.: Biogenic volatile organic compounds in the Earth system, New Phytol., 183, 27-51, 2009.

Lathière, J., Hewitt, C. N., and Beerling, D. J.: Sensitivity of isoprene emissions from the terrestrial biosphere to 20th century changes in atmospheric $\mathrm{CO}_{2}$ concentration, climate and land use, Global Biogeochem. Cycles, 24, GB1004, doi:10.1029/2009GB003548, 2010.

McCormick, M., Thomason, L., and Trepte, C.: Atmospheric effects of the Mount Pinatubo eruption, Nature, 373, 399-404, 1995.

Mercado, L. M., Belloui, N., Sitch, S., Boucher, O., Huntingford, C., Wild, M. and Cox, P. M.: Impact of changes in diffuse radiation on the global land carbon sink, Nature,458, 1014-1017, 2009.

Trahan N., Rosenstiel, T. N. Veres, P., Moore, D., Wilkinson, M., Norby, R. J., Volder, A., Tjoelker, M. G., Briske, D. D., Karnosky, D. F., and Fall, R.: Isoprene emission from terrestrial ecosystems in response to global change: minding the gap between models and observations, Phil. Trans. R. Soc., 365, 16771695, 2007.

Olmo, F. J., Tovar, J., Alados-Arboledas, L., Okulov, O., and Ohvril, O. H.: A comparison of ground level solar radiative effects of recent volcanic eruptions, Atmos. Environ., 33, 4589-4596, 1999.

Osborne, C. P. and Beerling, D. J.: A process-based model of conifer forest structure and function with special emphasis on leaf lifespan, Global Biogeochem. Cy., 16, 1097-1120, 2002.

Roderick, M. L., Farquhar, G. D., Berry, S. L., and Noble, I. R.: On the direct effect of clouds and atmospheric particles on the productivity and structure of vegetation, Oecologia, 129, 21-30, 2001.

Telford, P. J., Lathière, J., Abraham, N. L., Archibald, A. T., Braesicke, P., Johnson, C. E., Morgenstern, O., O’Connor, F. M., Pike, R. C., Wild, O., Young, P. J., Beerling, D. J., Hewitt, C. N., and Pyle, J.: Effects of climate-induced changes in isoprene emissions after the eruption of Mount Pinatubo, Atmos. Chem. Phys., 10, 7117-7125, doi:10.5194/acp-10-7117-2010, 2010.

Wild, M.: Global dimming and brightening: A review, J. Geophys. Res., 114, D00D16, doi:10.1029/2008JD011470, 2009.

Wythers, K. R., Reich, P. B. and Turner, D. P.: Predicting leaf area index from scaling principles: corroboration and consequences, Tree Physiol., 23, 1171-1179, 2003. 